\title{
A Climatological Study of Tropical Cyclone Rainfall in Vietnam
}

\author{
Hoang Anh Nguyen-Thi ${ }^{1,3}$, Jun Matsumoto ${ }^{1,2}$, Thanh Ngo-Duc ${ }^{4}$, and Nobuhiko Endo ${ }^{2}$ \\ ${ }^{1}$ Department of Geography, Tokyo Metropolitan University, Hachioji, Japan \\ ${ }^{2}$ Research Institute for Global Change, JAMSTEC, Yokosuka, Japan \\ ${ }^{3}$ Aero Meteorological Observatory, National Hydro-Meteorological Service, Hanoi, Vietnam \\ ${ }^{4}$ Department of Meteorology, Hanoi College of Science, Vietnam National University, Hanoi, Vietnam
}

\begin{abstract}
This study investigated the characteristics of the rainfall associated with tropical cyclones (TCs), using the TC best-track data and daily rainfall data from 15 meteorological stations for the period 1961-2008 for the coastal region of Vietnam. In addition to investigating the TC rainfall amount, we estimated the $\mathrm{TC}$ rain ratio and the ratio of TC heavy rainfall days (TC_R50) and interpreted these parameters for El Niño and La Niña years. Our results show that the maximum TC rainfall occurs from July to September in the northern region, whereas the total rainfall at southern stations is mainly composed of non-TC rainfall. The TC rainfall amount is concentrated in the central region, with a peak in October-November. The TC rain ratio varies from 0 to $\sim 25 \%$, showing a maximum value in the region of $16^{\circ} \mathrm{N}-18^{\circ} \mathrm{N}$ in September. The mid-central region of Vietnam has maximum TC_R50 ratio in September-October corresponding to its highest $\mathrm{TC}$ frequency in the same period. During El Niño (La Niña) years, the $\mathrm{TC}$ rain ratio and TC $\mathrm{R} 50$ ratio in the central region show a significant decrease (increase) in October-November. The La Niña phases more strongly affect TC rainfall than the El Niño phases, particularly in central Vietnam.
\end{abstract}

\section{Introduction}

Tropical cyclones (TCs) regularly threaten many countries, bringing dangers such as disastrously heavy rainfall and flooding. Several studies have examined the rainfall associated with TCs (hereafter called TC rainfall). For example, Rodgers et al. (2000) estimated TC rainfall in the North Pacific using Special Sensor Microwave Imager (SSM/I) observations for an 11-year period. They found that TCs contributed $12 \%$ of the climatological rainfall over the western North Pacific (WNP) from June to November. They also showed that TC rainfall increased from 12 to $18 \%$ during El Niño events. Englehart and Douglas (2001) investigated the role of tropical storms over the eastern North Pacific in the rainfall climatology of western Mexico and showed that tropical storm-associated rainfall normally constitutes 20 to $60 \%$ of rainfall along Mexico's Pacific coast. In more extreme cases, they found that such rainfall can contribute as much as 25 to $30 \%$ to seasonal rainfall totals in western interior locations. Gleason (2006) estimated the characteristics of TC rainfall in the United States between 1950 and 2004. They found that coastal and near-coastal regions received 8 to $16 \%$ and 4 to $12 \%$ of the precipitation by TCs, respectively. Ren et al. (2006) reported that the ratio of annual TC precipitation to total annual rainfall is 20 to $30 \%$ in most of Taiwan and along the coast of China south of $25^{\circ} \mathrm{N}$, using rain gauge data over China during 1971-2004. Kubota and Wang (2009) investigated the effect of TCs on seasonal and interannual rainfall variability over the WNP by analyzing rainfall data at 22 rain gauge stations. They showed that along $125^{\circ} \mathrm{E}$ and

Corresponding author: Hoang Anh Nguyen-Thi, Tokyo Metropolitan University, 1-1 Minami-Osawa, Hachioji, Tokyo 192-0397, Japan. E-mail: nguyen-hoanganh@ed.tmu.ac.jp. (C2012, the Meteorological Society of Japan. between $18^{\circ} \mathrm{N}$ and $26^{\circ} \mathrm{N}$, TC rain accounts for 50 to $60 \%$ of the total rainfall during the TC season from July to October. In addition, they described some characteristics of TC rainfall during the developing phases of El Niño and La Niña. Recently, Sugino and Satomura (2010) mapped precipitation due to typhoons in the period 1998-2004 over Indochina, based on Tropical Rainfall Measuring Mission (TRMM)-3B42 data. They showed that the maximum precipitation occurs along the eastern coast of Indochina, with the precipitation amount over land decreasing as distance from the coast increases.

Vietnam is located along the eastern coast of the Indochina Peninsula. It is separated from other parts of the peninsula by the Truong Son range, which runs parallel to the coast (Yokoi and Matsumoto 2008). Every year, TCs that originate within the South China Sea (SCS) and the WNP strongly affect Vietnam, with high frequency in the northern and central regions and low frequency in the southern region. According to Garcia (2002), Vietnam is struck by an average of four to six typhoons per year. Some previous studies have examined the link between rainfall and TC activity, between rainfall and El Niño/La Niña-Southern Oscillation (ENSO) for Vietnam. For example, Takahashi et al. (2009) used a 30-year simulation for September from 1966 to 1995 and found a weakening TC activity over the region, which caused the observed long-term decrease in September rainfall along the eastern coast of Vietnam. Yen et al. (2010) analyzed the observational based data in Vietnam and concluded that central Vietnam has more (less) rainfall in the La Niña (El Niño) years. However, little has been known about the TC rainfall in Vietnam and its relationship with some large scale oscillations. Therefore, this study aims to explore the characteristics of the climatological seasonal TC rainfall in Vietnam, including the amount, the TC rainfall ratio, and heavy rainfall events. We also investigated the differences in these parameters during ENSO years for the coastal region of Vietnam.

\section{Data used and method}

\subsection{Data used}

The SCS is part of the WNP, defined here as the ocean body between $0^{\circ} \mathrm{N}$ and $25^{\circ} \mathrm{N}$ and $100^{\circ} \mathrm{E}$ and $120^{\circ} \mathrm{E}$ (Goh and Chan 2010). TCs in the SCS are formed in two ways. Some originate within the region, while others enter from the WNP. To investigate TCs and associated rainfall in this region, two main data sources have been used: (1) TC best-track data from the UNISYS website (http://weather.unisys.com) provided through the Joint Typhoon Warning Center and (2) daily rainfall observed at 15 meteorological stations operated by the Vietnamese National HydroMeteorological Service (Supplementary Table 1). The reason to choose UNISYS over different available best track datasets such as Regional Specialized Meteorological Center (RSMC) Tokyo, International Best Track Archive for Climate Stewardship (IBTrACS) and the Shanghai Typhoon Institute (STI) is simply based on our familiarity with the data. Song et al. (2010) mentioned that differences in TC tracks among these data sets are negligibly small, while TC intensities could be relatively different. Therefore, which best track data sets to use is not a challenging problem because only TC tracks information is required in this study. 


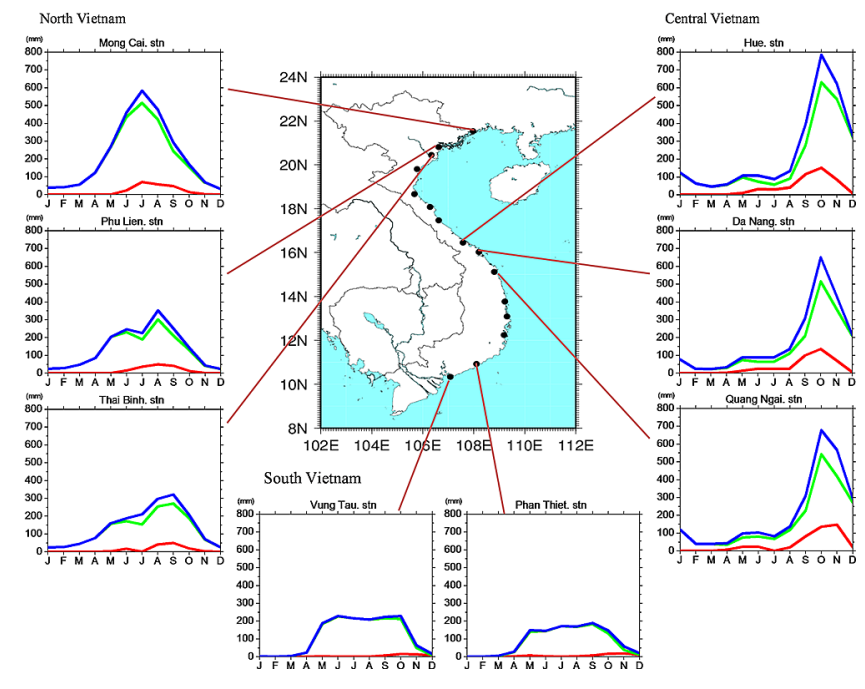

Fig. 1. Monthly climatological distribution of the total rainfall (blue), TC rainfall (red), and non-TC rainfall (green) of eight weather stations located in three Vietnam coastal regions (units are in $\mathrm{mm}$ ). The dots show the locations of the stations.

Figure 1 shows these stations and rainfall information. We selected TC best-track and daily rainfall data for the same period (1961-2008) and obtained information on El Niño-Southern Oscillation (ENSO) years from Kubota and Wang (2009) (Supplementary Table 2).

\subsection{Method}

Previous study used different distances from the TC center to define TC-induced rainfall. Englehart and Douglas (2001) found that in $90 \%$ of cases over western Mexico, TC rainfall occurs within $600 \mathrm{~km}$ from the center of the TC. Gleason (2006) estimated the characteristics of TC rainfall in the United States based on a simple partition method to consider rainfall associated with TCs. He treated any rainfall less than or equal to $600 \mathrm{~km}$ from the center of the storm as TC rainfall. Kubota and Wang (2009) assumed that the daily rainfall as a function of the distance between the TC center and stations and TC-induced rainfall could be estimated from station data when a TC was located within the radius of influence $(1000 \mathrm{~km})$. Hattori et al. (2010) showed the contribution of TCs to the seasonal change patterns of rainfall in the WNP, based on the Japanese 25-year Reanalysis (JRA-25) and Japan Meteorology Agency Climate Data Assimilation System (JRA-25/JCDAS) dataset (Onogi et al. 2007). In their study, TC rainfall was defined as the rainfall within $500 \mathrm{~km}$ of the center of the TC.

In this study, we used the distance of $600 \mathrm{~km}$ from the TC center to the station to investigate the TC rainfall contribution to the total rainfall (same as in Gleason 2006). The individual TC rainfall values were summed for each month at selected stations. The non-TC rainfall was defined as the difference between the total rainfall and the TC rainfall, while the TC rain ratio was defined as the TC rainfall divided by the total rainfall. In addition, heavy rainfall events caused by TCs were defined as days in which the daily rainfall amount exceeded $50 \mathrm{~mm} \mathrm{day}^{-1}$ (TC R50). In fact, $50 \mathrm{~mm} \mathrm{day}^{-1}$ is the heavy rainfall threshold currently used by the forecasters of the National Center for Hydro-Meteorological Forecasting of Vietnam, similar to the criteria of the Central Weather Bureau of Taiwan (Chen et al. 2007). TC_R50 ratio was defined as TC_R50 divided by the total heavy rainfall days (the sum of TC_R50 and non TC R50). Finally, the TC frequency was defined as the number of TCs that approached the station within the $600 \mathrm{~km}$ distance from the TC center.

In order to study the linkages of TC rainfall with ENSO years (Section 3.2), we used the bootstrapping technique detailed by
Efron and Tibshirani (1993). In this study, 1000 bootstrap replication of size $n_{\text {El Niño }}=18$ and $n_{\text {La Niña }}=13$ were generated to estimate anomalies during El Niño and La Niña years, respectively. The confidence intervals for bootstrap estimates were obtained using the percentile method.

\section{Results}

\subsection{Climatological seasonality of TC rainfall a. TC rainfall amount}

Figure 1 shows the mean distribution of TC rainfall, non-TC rainfall, and total rainfall amounts for each month at eight selected stations in three Vietnam coastal regions: north, central, and south. At most stations, TC rainfall is zero from December to May. In the northern part of Vietnam (from $20^{\circ} \mathrm{N}$ northward), the maximum TC rainfall occurs from July to September. In the central region (approximately from $12^{\circ} \mathrm{N}$ to $20^{\circ} \mathrm{N}$ ), the stations (includes the ones not shown in Fig. 1) have two total rainfall peaks. The first peak, which occurs in May, coincides with the active south-west monsoon period in the region. The second highest peak total rainfall appears in October-November, coinciding with the TC rainfall peak. In the central region, the non-TC rainfall amount contributes significantly to the total rainfall. This suggests that in addition to TC activity, other weather systems such as inter-tropical convergence zone (ITCZ) displacement, boreal summer and winter monsoon play an important role in this region (e.g., Chen et al. 2012; Yokoi and Matsumoto 2008). For the mid-central region (located between $15^{\circ} \mathrm{N}$ and $17^{\circ} \mathrm{N}$ ), Hue is the most typical station and has the highest TC rainfall $(152 \mathrm{~mm})$ in October among all analyzed stations in Vietnam. This result for the TC rainfall amount in the central region is close to the satellite data analyses by Jiang and Zipser (2010). However, in the southern part (from $12^{\circ} \mathrm{N}$ southward), the total rainfall is due mostly to non-TC rainfall. This region has both the minimum $\mathrm{TC}$ rainfall and minimum total rainfall in all of Vietnam. There, the rainy season coincides with the southwest monsoon season from May to October.

\section{b. $T C$ rain ratio and $T C$ R50 ratio}

The time-latitude sections of the monthly mean TC frequency and TC rain ratio are presented in Figs. $2 \mathrm{a}$ and $2 \mathrm{~b}$. The distribution of these factors is different from region to region and month to month. As indicated in Fig. 2a, the TC season starts from May-June. High TC frequency occurs in the central region from September to November, with a peak in October. From Fig. $2 \mathrm{~b}$, it can be seen that TC rain ratio contributes from 0 to $25 \%$, with the highest value found in the region of $16^{\circ} \mathrm{N}$ to $18^{\circ} \mathrm{N}$ in September. At three stations located in the mid-central region, the TC frequency reaches the maximum value in October, but the TC rain ratio in October is smaller than that in September because the total rainfall in October becomes maximum (Fig. 1). From $18^{\circ} \mathrm{N}$ northward, even though the TC frequency has a maximum value in September, the maximum TC rain ratio shifts to July, while the stations located south of $16^{\circ} \mathrm{N}$ have maximum ratios in November. In addition, the $\mathrm{TC}$ rain ratio south of $16^{\circ} \mathrm{N}$ reaches a maximum value in November due to both the high TC frequency and the low total rainfall.

Heavy rainfall events that can cause flooding and extensive damage, occur frequently during the rainy season in central Vietnam (Yokoi and Matsumoto 2008). To what extent do TCs contribute to these events? Figure $2 \mathrm{c}$ shows the time-latitude section of the monthly mean TC_R50 ratio. The value of TC_R50 ratio varies from north to south along the coastal line. TC_R50 ratio starts to increase in May, becoming greater during July-November. The northern region receives a maximum TC R50 ratio value up to $20 \%$ from July to October, whereas the southern region receives a low TC_R50 ratio value throughout the year. The maximum value of TC R50 ratio occurs in September, October in the midcentral region. This area also has the highest TC frequency (Fig. $2 a)$ in the same period. Hence, TCs play an important role both in rainfall and heavy rainfall events in that region.

During the TC season in Vietnam (from June to December, 
a) TC frequency

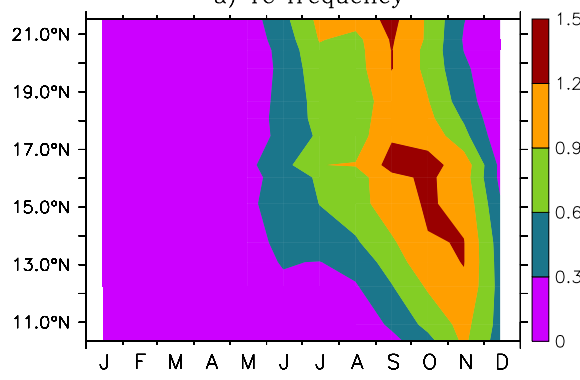

b) $\mathrm{TC}$ rain ratio $(\%)$

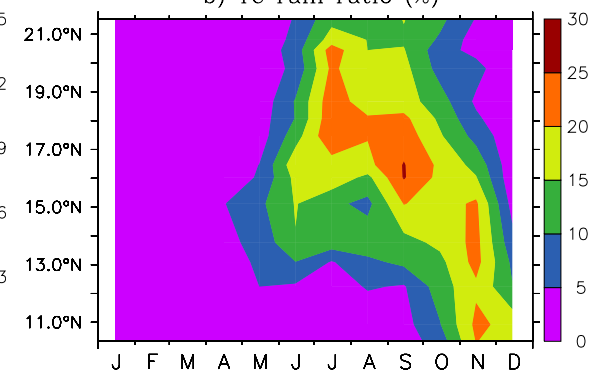

c) TC_R50 ratio (\%)

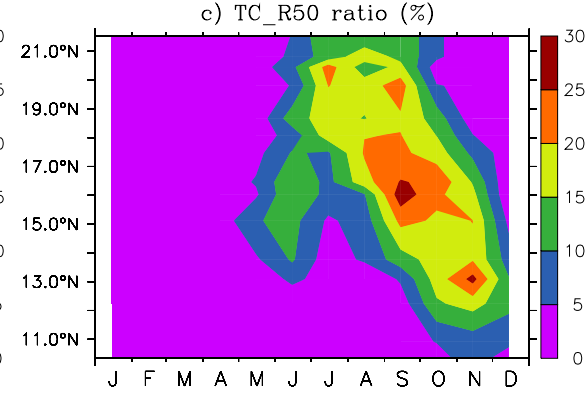

Fig. 2. Time-latitude sections of (a) TC frequency, (b) TC rain ratio, and (c) TC_R50 ratio along the Vietnam coast.

not shown), the mid-central region receives the maximum $\mathrm{TC}$ frequency (six cases), TC rain ratio $(\sim 26 \%)$, and TC_R50 ratio $(\sim 26 \%)$. These values decrease northward and southward along the Vietnamese coast.

\subsection{Linkages with ENSO years}

The association between ENSO and TC activity over the SCS/ WNP is well documented. Wang and Chan (2002) noted that the interannual variability of TC formation in the WNP is strongly affected by ENSO phases. Goh and Chan (2010) showed that the total number of TCs entering the SCS from the WNP is below normal during El Niño events but above normal during La Niña events. Kubota and Wang (2009) also reported that the seasonal $\mathrm{TC}$ rain ratio differs between El Niño and La Niña years.

In Figs. 3 and 4, we examined the anomalies of TC frequency, TC rain ratio, and TC R50 ratio during El Niño and La Niña years, respectively. The contour shows the mean bootstrap value of the anomalies while color shading shows areas where the anomalies is positively (negatively) significant at the $90 \%$ confidence level.

Figure 3a (Fig. 4a) shows that during El Niño (La Niña) years, TCs are significantly less (more) frequent than the climatology in October and November across all regions, which is in agreement with previous studies (Goh and Chan 2010; Wu et al. 2004). The decrease (increase) in TC frequency leads to a significant decrease (increase) of up to $20 \%$ in the TC rain ratio in October and November from $13^{\circ} \mathrm{N}$ northward (Figs. $3 \mathrm{~b}$ and $4 \mathrm{~b}$ ). During El Niño years, a significantly positive TC rain ratio anomaly appears in the mid-central region in September while negative TC rain ratio anomalies appear in July. Similar to TC rain ratio, an increase in TC_R50 ratio also occurs in mid-central region in September (Fig. 3c) ). Significant negative (positive) TC R50 ratio values are also found in the central region during late autumn in El Niño (La Niña) years (Figs. 3c and 4c).

Compared to the TC season (June to December) total distribution (not shown), less (more) TC frequency can be seen in all the coastal regions in Vietnam during El Niño (La Niña) years. The $\mathrm{TC}$ rain ratio and TC R50 ratio also decreases (increases) during El Niño (La Niña) years, except at stations located in the northern region. Anomalies in the TC rain ratio and TC $\mathrm{R} 50$ ratio in $\mathrm{La}$ Niña years are higher than those in El Niño years in the central region. The La Niña phases strongly affect TC rainfall, particularly in central Vietnam. a) TC frequency anomaly (El Niño)

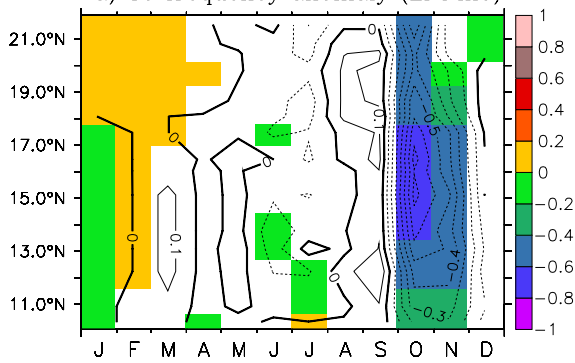

b) $\mathrm{TC}$ rain ratio anomaly (El Niño) (\%)

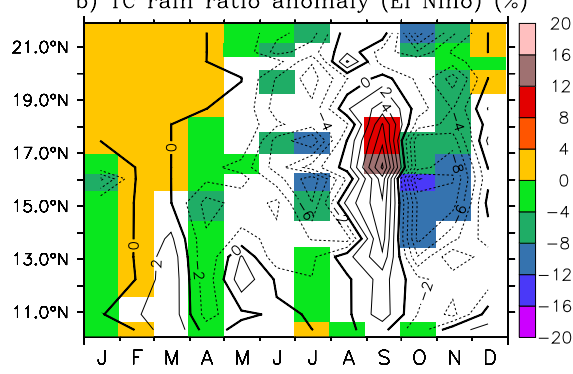

c) TC R50 ratio anomaly (El Niño) (\%)

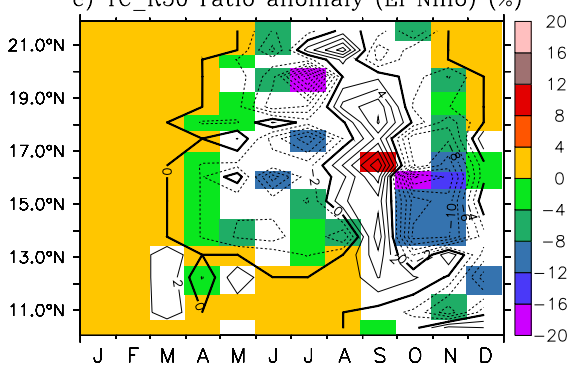

Fig. 3. Time-latitude sections of the bootstrap means (contour) of (a) TC frequency anomaly, (b) TC rain ratio anomaly, and (c) TC R50 ratio anomaly in El Niño years. Color shading shows areas where the anomalies is positively (negatively) significant at the $90 \%$ confidence level and the color levels also indicate the bootstrap means of each anomaly.

a) TC frequency anomaly (La Niña)

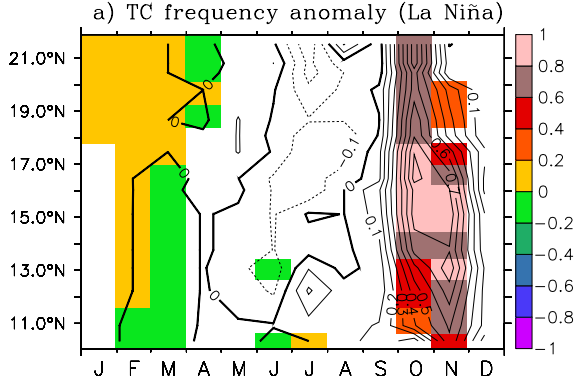

b) TC rain ratio anomaly (La Niña) (\%)

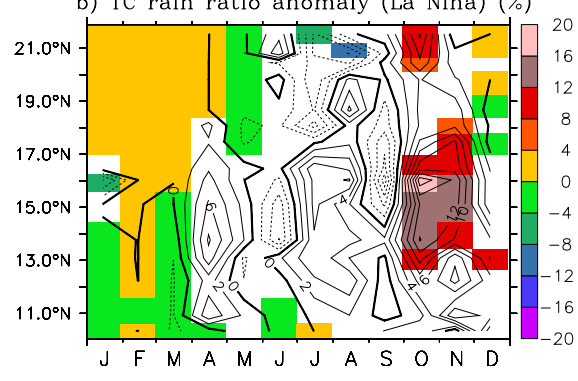

c) TC R50 ratio anomaly (La Niña) (\%)

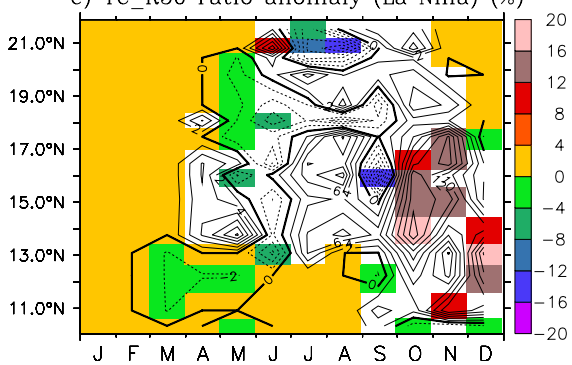

Fig. 4. Same as Fig. 3, but for La Niña years. 


\section{Conclusions}

By analyzing the TC best-track data from the UNISYS website archive and the daily rainfall data from 15 meteorological stations in the period 1961-2008, we explored the role of TCs in the rainfall climatology of the Vietnam coastal region. The distribution of TC rainfall, TC rain ratio, and the ratio of heavy rain days varies spatially and temporally. The TC rainfall amount in the central region is higher than that in other regions, with a peak in October-November. The northern region has maximum TC rainfall from July to September, whereas the total rainfall in the south is due mainly to non-TC rainfall. The TC rain ratio varies from 0 to $\sim 25 \%$ with a maximum value occurring from $16^{\circ} \mathrm{N}$ to $18^{\circ} \mathrm{N}$ in September. The mid-central region of Vietnam receives the maximum TC_R50 ratio in September-October and also has the highest $\mathrm{TC}$ frequency in the same period.

Distinct differences in El Niño and La Niña phases were found for both the TC rain ratio and TC R50 ratio. During El Niño (La Niña) years, the TC rain ratio and TC_R50 ratio significantly decrease (increase) in October-November in the central region, particularly the $15^{\circ} \mathrm{N}$ to $17^{\circ} \mathrm{N}$ region. Our results also emphasize that the La Niña phases more strongly affect TC rainfall than the El Niño phases, particularly in central Vietnam.

This study has not addressed the long-term change in TCinduced rainfall and changes in the atmospheric circulation forced by ENSO events. Further studies are needed to investigate these problems, to identify variations in TC rainfall, and to explain the differences between ENSO phases described here.

\section{Acknowledgements}

We thank the Vietnam Institute of Meteorology, Hydrology and Environment for providing the rainfall data. We are also grateful for comments and suggestions from Prof. Hideo Takahashi, Assistant Prof. Hiroshi Takahashi of the Department of Geography, Tokyo Metropolitan University, and Dr. Hisayuki Kubota of JAMSTEC/RIGC. This research is supported by the "Asian Human Resources Fund" from the Tokyo Metropolitan Government, the "Global Environment Research Fund" (no. A-0902) of the Japanese Ministry of the Environment, the 6th JAXA PMM Project No. 306, and the "Grant-in-Aid for Scientific Research" (no. 23240122) from the Japanese Ministry of Education, Culture, Sports, Science and Technology. We also thank the editor Associate Prof. Hironori Fudeyasu and two anonymous reviewers for their valuable comments and suggestions which greatly improved our manuscript.

\section{Supplements}

Supplement 1 is list of stations used in this study.

Supplement 2 is list of ENSO years used in this study.

\section{References}

Chen, T.-C., J.-D. Tsay, M.-C. Yen, and J. Matsumoto, 2012: Interannual variation of the late fall rainfall in central Vietnam. J. Climate, 25, 392-413.

Chen, C.-S., Y.-L. Chen, C.-L. Liu, P.-L. Lin, and W.-C. Chen, 2007: Statistics of heavy rainfall occurrences in Taiwan. Wea. Forecasting, 22, 981-1002.

Efron, B., and R. J. Tibshirani, 1993: An Introduction to the Bootstrap. Chapman and Hall, $436 \mathrm{pp}$.
Englenhart, P. J., and A. V. Douglas, 2001: The role of eastern North Pacific tropical storms in the rainfall climatology of western Mexico. Int. J. Climatol., 21, 1357-1370.

Garcia, L., 2002: Overview of Early Warning Systems for HydroMeteorological Hazards in Selected Countries in Southeast Asia. Asian Disaster Preparedness Center, Thailand, 51.

Gleason, B., 2006: Characteristics of tropical cyclone rainfall in the United States. 27th Conference on Hurricanes and Tropical Meteorology, Session 16C, Tropical Cyclones and Climate V-Atlantic Basin.

Goh, A. Z. C., and J. C. L. Chan, 2010: Interannual and interdecadal variations of tropical cyclone activity in the South China Sea. Int. J. Climatol., 30, 827-843.

Hattori, M., K. Tsuboki, and S. Mori, 2010: Contribution of tropical cyclones to the seasonal change patterns of precipitation in the western North Pacific: Estimation based on JRA-25/ JCDAS. SOLA, 6, 101-104.

Jiang, H., and E. J. Zipser, 2010: Contribution of tropical cyclones to the global precipitation from eight seasons of TRMM data: regional, seasonal, and interannual variations. J. Climate, 23, 1526-1543.

Kubota, H., and B. Wang, 2009: How much do tropical cyclones affect seasonal and interannual rainfall variability over the western North Pacific? J. Climate, 22, 5495-5510.

Onogi, K., J. Tsutsui, H. Koide, M. Sakamoto, S. Kobayashi, H. Hatsushika, T. Matsumoto, N. Yamazaki, H. Kamahori, K. Takahashi, S. Kadokura, K. Wada, K. Kato, R. Oyama, T. Ose, N. Mannoji, and R. Taira, 2007: The JRA-25 reanalysis. J. Meteor. Soc. Japan, 85, 369-432.

Ren, F., G. Wu, W. Dong, X. Wang, Y. Wang, W. Ai, and W. Li, 2006: Changes in tropical cyclone precipitation over China. Geophys. Res. Lett., 33, L20702, doi:10.1029/2006GL 027951.

Rodgers, E. B., R. F. Adler, and H. F. Pierce, 2000: Contribution of tropical cyclones to the North Pacific climatological rainfall as observed from satellites. J. Appl. Meteor, 39, 16581678.

Song, J.-J., Y. Wang, and L. Wu, 2010: Trend discrepancies among three best track data sets of western North Pacific tropical cyclones. J. Geophys. Res., 115, D12128, doi:10.1029/2009 JD013058

Sugino, M., and T. Satomura, 2010: Long-lived typhoons over Indochina. Journal of Research in Engineering and Technology, 7, 97-104.

Takahashi, H. G., T. Yoshikane, M. Hara, and T. Yasunari, 2009: High-resolution regional climate simulations of the longterm decrease in September rainfall over Indochina. Atmos. Sci. Let., 10, 14-18, doi:10.1002/asl.203.

Wang, B., and J. C. L. Chan, 2002: How strong ENSO events affect tropical storm activity over the western North Pacific. J. Climate, 15, 1643-1658.

Wu, M. C., W. L. Chang, and W. M. Leung, 2004: Impacts of El Niño-Southern oscillation events on tropical cyclone landfalling activity in the western North Pacific. J. Climate, 17, 1419-1428.

Yen, M. C., T. C. Chen, H. L. Hu, R. Y. Tzeng, D. T. Dinh, T. T. T. Nguyen, and C. J. Wong, 2010: Interannual variation of the fall rainfall in Central Vietnam. J. Meteor. Soc. Japan, 89A, 259-270, doi:10.2151/jmsj.2011-A16.

Yokoi, S., and J. Matsumoto, 2008: Collaborative effects of cold surge and tropical depression-type disturbance on heavy rainfall in central Vietnam. Mon. Wea. Rev., 136, 3275-3287.

Manuscript received 10 February 2012, accepted 10 April 2012

SOLA: http://www.jstage.jst.go.jp/browse/sola 